\title{
Effect of Actidione, Griseofulvin and Triphenyltin Acetate on the Kinetics of Fungal Growth
}

\author{
By A. P. J. TRINCI AND K. GULL \\ Microbiology Department, Queen Elizabeth College \\ (University of London), Campden Hill, London, W. 8
}

(Accepted for publication Io November 1969)

\begin{abstract}
S UMM A R Y
The colony radial growth rate and germ tube specific growth rate of Absidia glauca decreased linearly with the logarithm of actidione, triphenyltin acetate or griseofulvin concentration. Colony growth rate was directly related to the mould's specific growth rate in submerged culture over a 200-fold range of actidione concentration. The radial growth rate of Aspergillus nidulans colonies was not influenced by inoculum concentration but colony diameter was directly related to the logarithm of the inoculum concentration over the lower range.
\end{abstract}

\section{INTRODUCTION}

Although colony diameter and radial growth rate are frequently used to measure fungal growth in bioassays and physiological investigations (Cochrane, 1958), few critical studies have been made to evaluate these growth parameters. The rate of growth of a mould can be defined most precisely in terms of its specific growth rate $(\alpha)$ or doubling time $\left(t_{d}\right)$ in submerged culture. The specific growth rate of an organism may be calculated from the expression:

$$
\alpha=\operatorname{In~} 2 / t_{d},
$$

where $t_{d}$ is the doubling time. The reliability of colony radial growth rate as a parameter of growth may be assessed by determining its relationship to the specific growth rate of the mould in submerged culture under various cultural conditions. Using this criterion the radial growth rate of Aspergillus nidulans colonies is directly related to the mould's specific growth rate over a wide temperature range (Trinci, I969) and may thus be used to determine the optimum growth temperature for this, and presumably other, moulds. However, colony radial growth rate is not a suitable parameter to use to assess the relative growth rates of different mould species (Trinci, I969) or even mutants of the same species (Bainbridge \& Trinci, 1969). Similarly colony extension cannot be used as a meaningful assessment of growth in nutritional studies (Trinci, I969).

Variation in colony radial growth rate has frequently been used to measure the inhibitory effect of antifungal chemicals and the main object of this study was to determine if there was a correlation between the colony radial growth rate of a mould and its specific growth rate in submerged culture over a range of inhibitor concentration. In a previous study (Trinci, 1969) the value of germ tube specific growth rate as a parameter of mould growth was investigated. We continue this study in the present work. 
Three antifungal agents were used in this investigation-griseofulvin, actidione (cycloheximide) and triphenyltin acetate (TPTA). Actidione inhibits protein synthesis in eucaryotic organisms but the mode of action of TPTA and griseofulvin is unknown although it has been suggested that the latter interferes with chitin biosynthesis (Brian, 1949). Triphenyltin compounds have recently been used to control fungal pathogens of plants (Hislop, 1963; Stallknecht \& Calpouzos, 1968).

\section{METHODS}

Organisms. Aspergillus nidulans BWB 224 (Glasgow) recombinant ve y and Absidia glauca $(+)$, Queen Elizabeth College strain z 8 were used; A. glauca was grown at $25^{\circ}$ and $A$. nidulans at $37^{\circ}$.

Media. Aspergillus nidulans was grown on the DAN medium described previously (Trinci, I969). The composition of the medium (DPM) for Absidia glauca was (g./1.): D-glucose, I0; $\mathrm{KH}_{2} \mathrm{PO}_{4}, 3 \cdot 4 ; \mathrm{Na}_{2} \mathrm{HPO}_{4}$. $\mathrm{I}_{2} \mathrm{H}_{2} \mathrm{O}, 8 \cdot 9 ;\left(\mathrm{NH}_{4}\right)_{2} \mathrm{SO}_{4}, 6$; disodium ethylenediaminotetracetic acid (EDTA), $0.6 ; \mathrm{MgSO}_{4} \cdot 7 \mathrm{H}_{2} \mathrm{O}, 0.25 ; \mathrm{CaCl}_{2}, 0.05 ; \mathrm{ZnSO}_{4} \cdot 7 \mathrm{H}_{2} \mathrm{O}$, $0.2 ; \mathrm{MnSO}_{4} .4 \mathrm{H}_{2} \mathrm{O}, 0.02 ; \mathrm{CuSO}_{4} .5 \mathrm{H}_{2} \mathrm{O}, 0.005 ; \mathrm{FeSO}_{4} .7 \mathrm{H}_{2} \mathrm{O}, 0.1 ; \mathrm{Na}_{2} \mathrm{SO}_{4}, 0.5 ;$ $\mathrm{NaMoO}_{4}\left(2 \mathrm{H}_{2} \mathrm{O}\right), 0.005$; thiamine hydrochloride, 0.0005 . The $\mathrm{pH}$ of the medium was 6.8. The media were prepared in the manner described previously (Trinci, 1969).

Preparation of solutions of the growth inhibitors. Stock solutions of griseofulvin (Glaxo), $1000 \mathrm{mg} . / \mathrm{l}$, and triphenyltin acetate (kindly provided by $\mathrm{Mr} \mathrm{R}$. Barnes, Chemistry Department, Queen Elizabeth College), $100 \mathrm{mg} . / 1$., in ethanol were prepared separately. The stock solutions were diluted with ethanol so that the appropriate inhibitor concentration was obtained when $10 \mathrm{ml}$. was added to $200 \mathrm{ml}$. of medium. Molten agar was added to the other constituents held at $70^{\circ}$ in a water bath. The final concentration of ethanol in the medium was thus less than $5 \%$. The controls contained the same concentration of ethanol as the media with inhibitor. The stock solution (4000 mg./1.) of aqueous actidione (Upjohn, Kalamazoo, Michigan, U.S.A.) was sterilized by membrane filtration and diluted with sterile distilled water so that $20 \mathrm{ml}$. added to $\mathrm{I} 80 \mathrm{ml}$ of media gave the requisite inhibitor concentration.

Unless stated otherwise, all other methods are the same as those described previously (Trinci, 1969).

\section{RESULTS}

Effect of inoculum on colony diameter and radial growth rate

Two methods are widely used to assess the linear growth of fungal colonies on solid media, viz. colony diameter at a set time after inoculation (Brancato \& Golding, 1953) and colony radial growth rate (Lindenmayer \& Schoen, 1967). However, under certain circumstances, as shown below, these two methods do not give the same result.

A suspension of Aspergillus nidulans conidia $\left(4 \times 10^{7}\right.$ conidia $/ \mathrm{ml}$.) was serially diluted $\mathrm{I} / 4$ in sterile distilled water and each dilution was used to inoculate two plates. The diameters of the colonies $48 \mathrm{hr}$ after inoculation and their radial growth rates between 26 and 48 hr are shown in Fig. I. Although colony radial growth rate was not influenced by inoculum size, colony diameter increased linearly with the logarithm of the inoculum concentration up to 800 conidia $/ \mathrm{cm}^{2}$ (cf. Gillie, 1968). 
Effect of actidione, griseofulvin and triphenyltin acetate on colony radial growth rate

The effects of actidione, griseofulvin and triphenyltin acetate on the radial growth rate $\left(K_{r}\right)$ of Absidia glauca colonies are shown in Fig. 2. In each case the radial growth rate of the colonies decreased linearly with the logarithm of the inhibitor concentration.

Effect of actidione, griseofulvin and triphenyltin acetate on germ tube specific growth rate

In these experiments the diameter of the sporangiospore was included in all measurements and if a second germ tube was formed its length was also included (the spore usually produced only one or two germ tubes and rarely three).

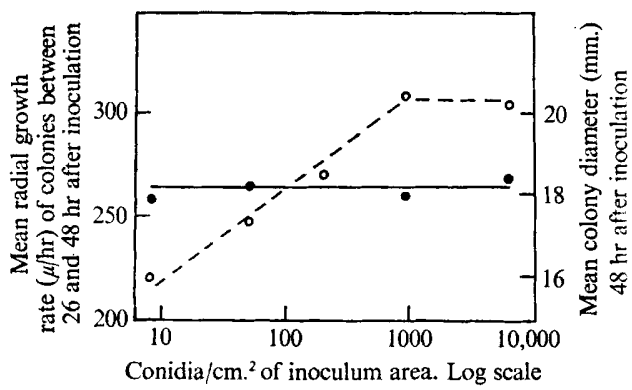

Fig. 1

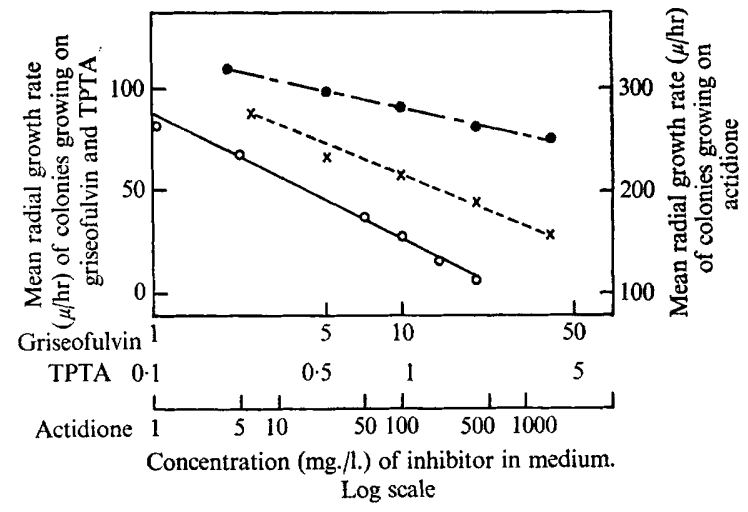

Fig. 2

Fig. I. Influence of inoculum concentration on the radial growth rate $(\bullet)$ and diameter (O) of Aspergillus nidulans colonies.

Fig. 2. Effect of actidione $(O)$, griseofulvin, $(\bullet)$ and triphenyltin acetate $(x)$ on the radial growth rate of Absidia glauca colonies.

The germ tubes of Absidia glauca sporangiospores, like those of Aspergillus nidulans conidia (Trinci, 1969), increased in length at an exponential rate as soon as germination commenced (Fig. 3). The specific growth rates of $A$. glauca germ tubes grown on the three inhibitors are shown in Fig. 4. In each case the germ tube specific growth rate decreased linearly with the logarithm of the inhibitor concentration.

Effect of actidione on colony radial growth rate and germ tube specific growth rate on solid media and on specific growth rate in submerged culture

The specific growth rate $\left(\alpha_{s}\right)$ of Absidia glauca grown in submerged culture on media containing various concentrations of actidione was determined in the manner described previously (Trinci, I969). The results are presented in Table I together with the ratios colony radial growth rate: specific growth rate in submerged culture $\left(K_{r} / \alpha_{s}\right)$ colony radial growth rate: germ tube specific growth rate $\left(K_{r} / \alpha_{g}\right)$ and germ tube specific growth rate: specific growth rate in submerged culture $\left(\alpha_{g} / \alpha_{s}\right)$ and the corresponding correlation coefficients. The extension rate of $A$. glauca colonies was directly related to the mould's specific growth rate in submerged culture over the range of actidione concentration tested. 
The $\alpha_{g} / \alpha_{s}$ ratio of 5.1 for Absidia glauca growing on media lacking actidione is similar to the value 5.9 obtained with Mucor hiemalis (Trinci, 1969), another Phycomycete. It is not known why the germ tube specific growth rate of an organism is consistently higher than its specific growth rate in submerged culture.

The $K_{r} / \alpha_{g}$ ratios and correlation coefficients for Absidia glauca growing on media containing griseofulvin and triphenyltin acetate are shown in Table 2: for both inhibitors the correlation was statistically significant.

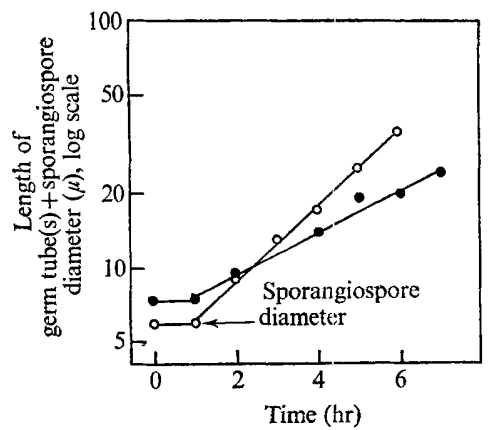

Fig. 3

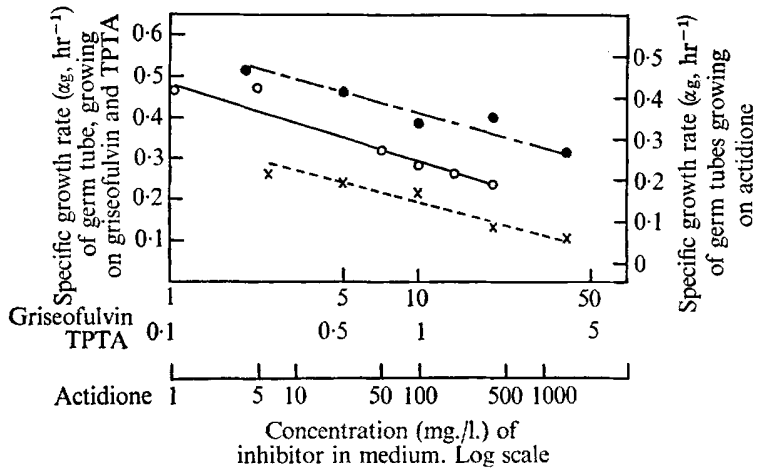

Fig. 4

Fig. 3. Germ tube growth of Absidia glauca sporangiospores on media lacking $(O)$ and containing $200 \mathrm{mg}$./1. actidione $(\bullet)$.

Fig. 4. Effect of actidione (O), griseofulvin (e) and triphenyltin acetate $(x)$ on the specific growth rate of Absidia glauca germ tubes.

Table I. Effect of actidione on colony radial growth rate and germ tube specific growth rate of Absidia glauca on solid medium and specific growth rate in submerged culture at $25^{\circ}$.

\begin{tabular}{|c|c|c|c|c|c|c|c|c|}
\hline \multirow[b]{2}{*}{$\begin{array}{c}\text { Actidione } \\
\text { concentration } \\
\text { (mg./l.) }\end{array}$} & \multirow[b]{2}{*}{$\begin{array}{l}\text { Colony radial } \\
\text { growth rate } \\
\left(K_{r}, \mu / \mathrm{hr}\right)^{*}\end{array}$} & \multicolumn{2}{|c|}{$\begin{array}{c}\text { Growth in } \\
\text { submerged culture }\end{array}$} & \multicolumn{2}{|c|}{ Germ tube growth } & \multirow[b]{2}{*}{$\begin{array}{l}1 \mathrm{I}^{-4} \\
\times K_{r} / \alpha_{3}\end{array}$} & \multirow[b]{2}{*}{$\begin{array}{l}\text { Ratios } 10^{-3} \\
\times K_{r} / \alpha_{g}\end{array}$} & \multirow[b]{2}{*}{$\alpha_{g} / \alpha$} \\
\hline & & $\begin{array}{c}\text { Specific } \\
\text { growth rate } \\
\left(\alpha_{s}, h^{-1}\right)\end{array}$ & $\begin{array}{c}\text { Doubling } \\
\text { time } \\
\left(t_{d s}, \mathrm{hr}\right)\end{array}$ & $\begin{array}{c}\text { Specific } \\
\text { growth rate } \\
\left(\alpha \mathrm{g}, \mathrm{hr}^{-1}\right) \dagger\end{array}$ & $\begin{array}{c}\text { Doubling } \\
\text { time } \\
\left(t_{d g}, \mathrm{hr}\right)\end{array}$ & & & \\
\hline 0 & 274 & 0.075 & $9 \cdot 2$ & 0.385 & $\mathrm{I} \cdot 8$ & $3 \cdot 7$ & $7 \cdot \mathbf{I}$ & $5 \cdot I$ \\
\hline I & 265 & 0.067 & 10.4 & 0.365 & $1 \cdot 9$ & 3.9 & $7 \cdot 3$ & $5 \cdot 4$ \\
\hline 5 & 236 & 0.063 & II $\cdot 0$ & 0.385 & $1 \cdot 8$ & $3 \cdot 7$ & $6 \cdot 1$ & 6.1 \\
\hline 50 & 175 & 0.059 & I I 8 & 0.226 & $2 \cdot 7$ & 3.0 & $7 \cdot 7$ & $3 \cdot 8$ \\
\hline 100 & I 56 & 0.042 & $16 \cdot 4$ & 0.187 & $3 \cdot 7$ & $3 \cdot 7$ & $8 \cdot 3$ & 4.5 \\
\hline 200 & 132 & 0.034 & $20 \cdot \mathrm{I}$ & 0.169 & $4^{\cdot I}$ & 3.9 & $7 \cdot 8$ & 5.0 \\
\hline 400 & I 4 & - & - & 0.144 & $4 \cdot 8$ & - & $7 \cdot 9$ & - \\
\hline
\end{tabular}

* $K_{r}$, each rate is the mean of 12 colonies from 2 separate experiments.

$\dagger \alpha_{g}$, each rate is the mean of 5 to II germ tubes from at least 3 separate experiments.

$\ddagger \alpha_{s}$, each rate is the mean of 3 separate experiments.

Ratio means: $K_{r} / \alpha_{s}-3.7 ; K_{r} / \alpha_{g}-7.5 ; \alpha_{g} / \alpha_{s}-5.0$.

Correlation coefficients, $K_{r} / \alpha_{s}-0.84 \S ; K_{r} / \alpha_{q}-0.66 ; \alpha_{g} / \alpha_{s}-0.96 \S$

$\S$ Significant at $5 \%$ level of probability. 
Comparison between the colony radial growth rates on freshly prepared and old media containing actidione

Actidione not only causes a decrease in the radial growth rate of Absidia glauca colonies but also increases the lag between inoculation and spore germination (Fig. 5). In the previous experiments there may have been a reduction in the effective antibiotic concentration during the prolonged lag phase at certain actidione concentrations,

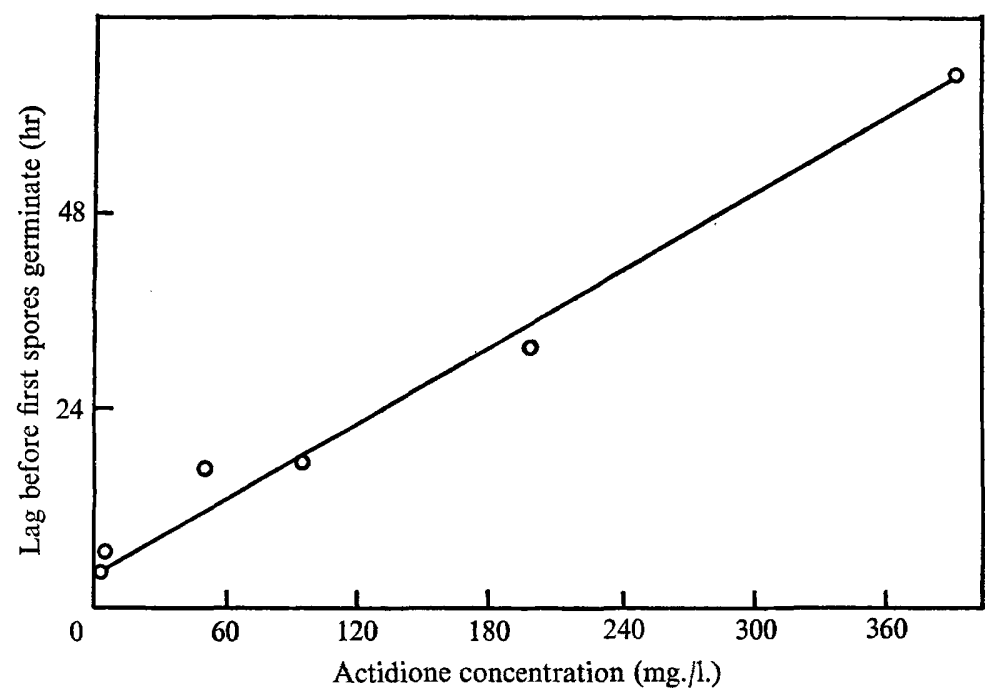

Fig. 5. Effect of actidione on the duration of the lag between inoculation and the germination of the first sporangiospores of Absidia glauca.

Table 2. Values for the ratio colony radial growth rate: germ tube specific growth rate $\left(K_{r} / \alpha_{g}\right)$ for Absidia glauca cultured on various concentrations of griseofulvin and triphenyltin acetate

$\begin{array}{cc}\begin{array}{c}\text { Griseofulvin } \\ \text { concentration } \\ \text { (mg./l.) }\end{array} & 1 \mathrm{O}^{-2} \times K_{r} / \alpha_{g} \\ 0 & 2 \cdot 2 \\ 2 & 2 \cdot 1 \\ 5 & 2 \cdot \mathrm{I} \\ 10 & 2 \cdot 3 \\ 20 & 2 \cdot 0 \\ 40 & 2 \cdot 4\end{array}$

$\begin{array}{cc}\begin{array}{c}\text { Triphenyltin } \\ \text { acetate } \\ \text { concentration } \\ \text { (mg./l.) }\end{array} & 10^{-2} \times K_{r} / \alpha_{g} \\ 0 & 2.5 \\ 0.25 & 3.4 \\ 0.50 & 2.7 \\ 1 \cdot 0 & 2.7 \\ 2.0 & 3.5 \\ 4.0 & 2.6\end{array}$

Correlation coefficients: $K_{r} / \alpha_{g}$ on griseofulvin $=0.89, K_{r} / \alpha_{g}$ on triphenyltin acetate $=0.90$. Both are significant at the $5 \%$ level of probability.

and this in turn may have influenced the type of growth response obtained. The stability of actidione at the incubation temperature was tested by comparing the growth rate of colonies cultured on media (containing 5 to $400 \mathrm{mg}$./actiodine $\mathrm{ml}$.) which had been kept for 8 days at $25^{\circ}$ before inoculation, with colonies grown on freshly prepared media. No significant difference was observed between the degree of growth inhibition, 
which indicates that even after 8 days at $25^{\circ}$ there was no appreciable degradation of actidione.

\section{DISCUSSION}

The present study indicates that colony radial growth rate is preferable to colony diameter as a means of assessing the effect of inhibitors on growth. Actidione influences the lag as well as having an effect on growth rate and thus the diameter of a colony is determined by the sum of these two effects. In this case, at least, the inhibitor influences the kinetics of these processes in different ways. Further, colony diameter, unlike colony radial growth rate, is influenced by the concentration of the inoculum. In the case of inocula containing 800 conidia $/ \mathrm{cm}^{2}$. or above, growth of the colony was probably initiated at the circumference of the inoculum immediately after germination but at lower inoculum concentrations, time would elapse whilst the mycelium first covered the inoculum area. Colony radial growth rate increases linearly with the logarithm of concentration of the growth-limiting nutrient (Gillie, I968; Trinci, 1969). The present study shows that colony radial growth rate decreases linearly with the logarithm of the concentration of an inhibitor in the medium. The bases of these two relationships is not known. They may, however, be of value in establishing bioassays for vitamins or antifungal chemicals. A linear relationship between colony growth and the logarithm of griseofulvin concentration has previously been reported by Lenhart (I968).

The growth rate of Absidia glauca colonies was directly related to the mould's specific growth rate in submerged cultures over a 200-fold range of actidione concentration. Colony radial growth rate would thus seem to be a reliable parameter to use to determine the effect of an inhibitor on fungal growth.

We would like to thank Dr B. W. Bainbridge for helpful discussion during the preparation of this paper.

\section{REFERENCES}

Bainbridge, B. W. \& Trinci, A. P. J. (I969). Colony and specific growth rates of normal and mutant strains of Aspergillus nidulans. Transactions of the British Mycological Society 53, 473.

Brancato, F. P. \& Golding, N. S. (1953). The diameter of the mould colony as a reliable measure of growth. Mycologia 45, 848 .

Brian, P. W. (1949). Studies on the biological activity of griseofulvin. Annals of Botany 19, 59.

Cochrane, V. W. (1958). Physiology of the Fungi. London: John Wiley and Sons Ltd.

GILlIE, O. J. (1968). Observations on the tube method of measuring growth rate in Neurospora crassa. Journal of General Microbiology 51, I 85.

Hislop, E. C. (1963). Studies on the chemical control of Phytophora palmivora (Butl.) on Theobroma cacao L. in Nigeria. IV. Further laboratory and field trials of fungicides. Annals of Applied Biology 52, 465 .

LENHART, K. (1968). Determination of griseofulvin sensitivity by mycelial growth test. Mykosen II, I95.

Lindenmayer, A. \& SchoEN, H. F. (1967). Selective effects of purine and pyrimidine analogues and of respiratory inhibitors on perithecial development and branching in Sordaria. Plant Physiology, Lancaster 42, I059.

Stallknecht, G. F. \& Calpouzos, L. (1968). Fungicidal action of triphenyltin hydroxide towards Cercospora beticola on sugar beet leaves. Phytopathology 58, 788.

TRINCI, A. P. J. (1969). A kinetic study of the growth of Aspergillus nidulans and other fungi. Journal of General Microbiology 57, I I. 